\title{
PERCEPÇÃO DE ECOSSISTEMA VIVENCIADO PELOS ALUNOS DO 60 ANO DA EMEF 21 DE ABRIL, PANAMBI-RS.
}

\author{
Adriana Maria de Souza Lang ${ }^{1}$, Dionísio Link ${ }^{2}$ \\ ${ }^{1}$ Graduada em Biologia, especialista em Psicopedagogia Institucional, professora da rede municipal de ensino de \\ Panambi, RS e aluna do Curso de Especialização em Educação Ambiental, UFSM, Autora. adriana.m.lang@gmail.com \\ ${ }^{2}$ Professor Titular, Dr., Departamento de Defesa Fitossanitária, Centro de Ciências Rurais, Universidade Federal de \\ Santa Maria (UFSM), Orientador. dlink@smail.ufsm.br.
}

\section{RESUMO}

Este trabalho tem por objetivo geral usar o olhar do educador ambiental como apoio aos alunos do 60 ano do Ensino Fundamental, para sensibilizar os adultos com que convivem, visando sua conscientização e mudança de atitudes em relação ao ambiente. Os envolvidos na pesquisa são os alunos do 6ㅇ ano da EMEF 21 de Abril, da cidade de Panambi- RS e seus pais e/ou responsáveis. Analisando questões sobre o local onde vivem e como estão percebendo a exploração do ambiente pelo homem, o estudo estabelece diálogo sobre o papel de cada pessoa na preservação; discute a educação ambiental como um todo, o processo em que ela se encontra atualmente e a responsabilidade de cada um, relacionando com estudos de diversos autores, na perspectiva de contribuir para avanços, conquistas e desafios. Os resultados obtidos mostram que os alunos compreendem que há desafios a serem superados e ações a serem colocadas em prática, para acontecer uma mudança de comportamento com relação ao meio ambiente.

Palavras-chave: Educação Ambiental. Meio Ambiente. Sensibilização.

\section{ABSTRACT}

This study has the overall objective use the sight of environmental educator to support students in 6th grade of elementary school, to educate adults with whom they live, seeking their awareness and change attitudes. Those involved in the research are the students of 6th grade of EMEF 21 de Abril, Panambi-RS and their parents or guardians. Analyzing the questions about where they live, and how they are perceived exploitation of the environment by man, we establish dialogue on the role of each person in its preservation. We raised the discussion about the Environmental Education as a whole, the process in which she is presently in, and responsibility of each one, relating to studies of various authors on the subject, contributing to progress, achievements and challenges of environmental education. The results showed that students understand that there are challenges to be overcome, actions to be put in place to happen a change of behavior with respect to the environment.

Keywords: Environmental Education. Environment. Awareness. 


\section{INTRODUÇÃO}

O município de Panambi/RS vem tendo um crescimento populacional nos últimos anos devido ao avanço industrial. No Bairro Zona Norte localiza-se a Agrovila, pensada inicialmente como construção de moradias para pessoas de baixa renda que trabalhariam na terra e com ela conseguiriam sua subsistência. Isso não aconteceu, pois as pessoas que ali foram morar trabalham no centro da cidade, nas lojas ou nas indústrias locais. Vizinho a esta área, encontra-se um local de banhado, rico ecossistema com fauna e flora variada, que agora foi loteado, para suprir a necessidade de construção de novas moradias, pela chegada do Instituto Federal Farroupilha ao Município. O loteamento compõe-se de moradia para famílias com crianças em idade escolar, sendo que a maioria estuda na EMEF 21 de Abril, na localidade de Rincão Fundo, a dez quilômetros do centro da cidade de Panambi, atendendo desde a educação infantil até o nono ano.

O presente artigo parte do seguinte problema: reconhecer o meio ambiente como espaço de convivência dos seres vivos, apontando possibilidades e atitudes de conservação e preservação desse meio como um todo; contribuindo, assim, para a sensibilização sobre a importância do cuidado com a água, o saneamento, a saúde da população do local, bem como sobre os impactos sociais das doenças e de outros problemas que ocorrem devido à falta desse cuidado. $O$ objetivo geral é usar o olhar do educador ambiental como apoio aos alunos do 60 ano do Ensino Fundamental, para sensibilizar os adultos com os quais convivem na busca de sua conscientização e mudança de mentalidade para com o meio em que vivem.

A pesquisa foi realizada através do método pesquisa-ação, com objetivo exploratório, o procedimento ocorreu através de pesquisa bibliográfica e de campo, para que se conhecesse o meio físico com de coleta de informações e com dados de questionário fechado aos alunos do 6o ano da Escola. Os dados foram analisados de forma quantitativa pela frequência das respostas aos questionários, realizados no dia 19 de abril de 2011. Após o levantamento, ocorreu o segundo encontro, no dia 03 de maio, ao qual foram levados materiais para pesquisa, bibliografia variada, desde dados em livros, anais de congressos, observação de fotografias, mapas topográficos, reportagens de jornais locais e de sites do Google sobre o tema em estudo, bem como bibliografias do Instituto Brasileiro do Meio Ambiente e dos Recursos Naturais Renováveis IBAMA e Fundação Estadual de Proteção Ambiental - FEPAM. Essa atividade culminou com a produção de cartilha, elaborada pelos alunos com os conhecimentos adquiridos.

\section{EDUCAÇÃO AMBIENTAL}

A educação ambiental vem sendo trabalhada cada vez mais nas escolas, sua marca principal está em afirmar a necessidade de vinculação dos processos ecológicos aos sociais na leitura do mundo, na forma de intervir na realidade e de existir na natureza. Loureiro:

Reconhece, portanto, que nos relacionamos na natureza por mediações que são sociais, ou seja, por meio de dimensões que criamos na própria dinâmica de nossa espécie e que nos formam ao longo da vida (cultura, educação, classe social, instituições, família, gênero, etnia, nacionalidade etc.). Somos sínteses singulares de relações, unidade complexa que envolve estrutura biológica, criação simbólica e ação transformadora da natureza. (LOUREIRO, 2007, p. 66). 
Questiona-se como respeitar a natureza nos dias atuais em que prevalece o consumismo e a desvalorização do ambiente em que se vive, uma vez que, como o filósofo Malvezzi relata:

Foi o modo racionalista que dessacralizou a natureza e, dessa forma, estabeleceu a ruptura entre o ser humano e o ambiente onde ele vive. Se essa dessacralização foi fundamental para a evolução da ciência, foi mortal para a natureza. A vida está de tal modo artificializada que qualquer pessoa criada numa grande cidade pouco sabe de onde vem a água que bebe, as essências de remédios e cosméticos, a madeira que está em seus móveis e só pergunta pelo ar que respira quando ele fede ou lhe traz alguma doença. ( MALVEZZI, 2007, p. 9).

Percebe-se que o ser humano está destruindo o Planeta e, consciente ou não, faz isso de maneira cada vez mais perversa, contribuindo com o aquecimento global, a destruição dos biomas, a constante degradação do ambiente com a poluição do solo, da água e do ar. Os problemas vão além do ecológico, são sociais, culturais, políticos e econômicos. Depende-se do meio ambiente para viver, para garantir a sobrevivência no Planeta, principalmente dos que ainda virão habitá-lo. Por isso, cada um deve fazer a sua parte, pela revisão de valores e atitudes, compreendendo que o desenvolvimento sustentável nunca acontecerá caso se deixe acontecer a degradação do meio ambiente em que se vive.

Para tanto, a melhor forma é iniciar-se com as crianças, pois com elas como parte atuante do desenvolvimento social, econômico, cultural e ambiental desde hoje, será mais fácil a consciência sustentável do amanhã. Para que se tenha equilíbrio, conforme Loureiro (2007), precisa-se desenvolver a educação ambiental, seja ela formal (desenvolvida nas escolas) ou não formal (pela utilização da mídia). A educação ambiental precisa vincular os processos ecológicos aos sociais, na leitura de mundo, na forma de intervir na realidade e de existir na natureza.

A educação ambiental formal tem o papel de mediar a relação da natureza com ações sociais, para formar um cidadão dinâmico que consiga perceber a importância do ambiente de várias maneiras em/na sua vida, como em cultura, educação, classe social, instituições, família, gênero, etnia, nacionalidade, entre outros. Com essa visão, deve-se desmistificar a forma de compreender a educação ambiental, como não sendo mais de uso exclusivo de ensino de conteúdo e conhecimentos biológicos com cunho ecológico, simples transmissão de conhecimentos e condutas ecologicamente corretas, com a sensibilização para a beleza da natureza. Hoje precisa se fazer entender a necessidade social de mudar atitudes, habilidades e valores e não somente comportamentos.

A prática escolar exige o conhecimento da posição ocupada pelo aluno na estrutura econômica, na dinâmica da instituição escolar e suas regras; além do conhecimento da especificidade cultural do grupo social com o qual se trabalha. Muitas vezes se pensa que se está certo e isso não acontece, precisa-se admitir que erros, incertezas, inquietações e dificuldades ocorrem no processo de transformação da realidade e de constituição dos sujeitos, sendo necessário refletir sobre o que se faz e se busca na educação. (LOUREIRO, 2007).

A educação ambiental é complexa e o papel do educador ambiental é levar ao entendimento da natureza, da sociedade, do ser humano e da educação de forma transdisciplinar com as áreas do conhecimento, sejam sociais, naturais, filosóficas, interagindo e construindo pontes e saberes; estabelecendo relações com currículo, conteúdos, atividades extracurriculares, relação escolacomunidade, projeto político-pedagógico, bem como com a política educacional, de formação de professores, de relação educação-trabalho-mercado, além de diretrizes curriculares. 


\title{
REMOA
}

O maior desafio da educação ambiental não é a certeza dos resultados, mas sim a construção permanente de novas possibilidades e reflexões que garantam o aprendizado, o respeito às múltiplas formas de vida e ao Planeta, construindo um mundo melhor para todos, igualitário, culturalmente diverso e ecologicamente viável. Prado define que:

\begin{abstract}
Um programa de educação ambiental para ser efetivo deve promover, simultaneamente, o desenvolvimento de conhecimento, de atitudes e de habilidades necessárias à preservação e melhoria da qualidade ambiental. Utiliza-se como laboratório o metabolismo urbano e seus recursos naturais e físicos, iniciando pela escola, expandindose pela circunvizinhança e sucessivamente até a cidade, a região, o país, o continente e o planeta. A aprendizagem será mais efetiva se as atividades estiverem adaptadas às situações da vida real da cidade ou do meio em que vivem alunos e professores. (PRADO, 2010).
\end{abstract}

Ao refletir sobre esses assuntos, vê-se a necessidade de que haja um debate sobre as formas de ocupação do solo, para que as pessoas de baixa renda possam sair das áreas impróprias para a habitação e tenham acesso a terrenos com infraestrutura adequada, com saneamento básico, água com qualidade e tratada, trabalho, escola, saúde e lazer. Isso posto que uma vida com qualidade requer o mínimo de dignidade, o que está expresso na afirmação abaixo:

As atividades socioeconômicas e o mundo do trabalho são a dimensão central do desenvolvimento, especialmente pelas contradições do avanço da lógica do mercado e pelos desequilíbrios e desigualdades produzidos pela primazia da acumulação capitalista em suas formas de especulação, competição e exclusão. (LAMPARELI, 1999, p. 231).

As cidades são obra do homem, que traz consigo os problemas como de falta de estudos e os coloca na urbanização; por outro lado, ao prestar mais atenção à natureza, se aprende a respeitála, pois a mesma ensina a se viver em equilíbrio. É dever de cidadão contribuir para que a cidade tenha qualidade de vida e é direito se posicionar diante dos problemas causados pelo mau uso do espaço urbano, cobrando providências das autoridades. É muito importante que se entendam quais são os problemas enfrentados pela cidade em que se vive e que se faça o que estiver ao alcance para ajudar a solucioná-los. São pequenos passos dados, mas ainda faltam muito debate e estudo, que vêm com a população pressionando o poder público pelos seus direitos.

\section{A poluição e a educação}

Procurando o significado da palavra poluição, verificou-se que é a emissão de resíduos sólidos, líquidos e gasosos em volume superior à capacidade de absorção do ambiente. Portanto, todas as substâncias estranhas e em excesso na natureza são poluidoras. Mas o que importa realmente é que a natureza está saturada de resíduos e dejetos que estão sendo lançados indiscriminadamente em seu solo, água e ar, por seres humanos. (ZOCCHI, 2010).

Nishijima (2010) colocou que a poluição vai muito além de pura emissão de resíduos, ela causa muitos prejuízos à saúde do ser humano:

A poluição é uma alteração indesejável nas características físicas, químicas ou biológicas da atmosfera, litosfera ou hidrosfera que cause ou possa causar prejuízo à saúde, à sobrevivência ou às atividades dos seres humanos e outras espécies. O conceito de poluição é associado às alterações indesejáveis provocadas pelas atividades e intervenções humanas no ambiente. (NISHIJIMA, 2010, p. 13). 
REMOA

O ser humano, por dizer-se pensante, deveria ter um cuidado maior com o bem dado / deixado pelos antepassados e que agora está em desequilíbrio, sendo destruído sem dó nem piedade. Mas com a população do Planeta crescendo diariamente, também acontece o aumento do consumo de matérias que são transformadas para atender às necessidades do homem de forma que resíduos sólidos e líquidos estão sendo uma ameaça ao ambiente.

O acúmulo de lixo - que virou um problema global - provoca a poluição e a contaminação do solo e da água, a liberação de gases do efeito estufa e a proliferação de insetos transmissores de doenças, conforme Zocchi (2010). Têm-se consciência desse fato e mesmo assim se continua a descartar resíduos sem pensar no mal que se está fazendo. Os efeitos da poluição podem ser vistos e localizados em determinadas áreas, regiões ou de forma globalizada, sendo que os mais perceptíveis são os locais e regionais, pois acontecem em lugares com grandes populações, em atividades agrícolas ou industriais.

Conforme o IBGE, no Brasil, em 2000, 73\% do lixo foi levado a aterro sanitário, garantindo maior controle da poluição ambiental, ou a aterros controlados, quando o lixo é coberto com uma camada de terra. O restante é jogado em lixões, terrenos baldios, matas e na beira de rios. (ZOCCHI, 2010).

Nishijima (2010) conduz à reflexão sobre o papel da educação ambiental para conscientizar o homem em relação ao ambiente, na compreensão de que é o meio de mudanças e, assim, conhecer sua responsabilidade nessa e em outras questões relativas à sobrevivência do Planeta.

\section{Água, saneamento e doenças}

Os problemas encontrados no ambiente são ocasionados pelo aumento da população nas regiões urbanas das cidades, muitas vezes não estruturadas, o que faz com que a falta de saneamento básico seja percebida drasticamente, pois inclui o não fornecimento de água limpa nem de tratamento de esgoto a todos os moradores do local. Sabe-se que o ser vivo não sobrevive sem a água, mas o homem continua destruindo o que ainda resta de água adequada para consumo sem pensar nas consequências. Também se sabe que apenas $1 \%$ da água de todo o Planeta é própria para o consumo, a chamada água doce, que está presente nos rios, lagos, poços, nuvens e na umidade do solo onde vivem os animais terrestres. Essa água não é exatamente doce, mas como a quantidade de sais dissolvida nela é menor do que a água do mar, recebeu esse nome, segundo Chiaradia (2003).

A água encontrada no ambiente nem sempre é pura, pois como se sabe ela é composta por moléculas de oxigênio e hidrogênio e recebe misturas como os sais minerais, tornando-se assim uma mistura, o que esclarece Chiaradia:

Na verdade, toda a água encontrada na forma líquida na natureza é uma mistura. A água é, pois, uma substância pura formada por um conjunto de moléculas todas iguais entre si: cada uma destas moléculas, por sua vez, é formada por dois tipos de átomos diferentes: o hidrogênio e o oxigênio. (CHIARADIA, 2003, p. 47).

A água recebida nas casas diariamente, na zona urbana das cidades, é tratada, pois foi captada em rios e se não passar por um processo de purificação manterá ativas as impurezas que a tornam imprópria para o consumo. Já a consumida na zona rural provém de poços de abastecimento, podendo ser rasos, que são mais frequentes e mais baratos; ou profundos também denominados artesianos, que captam água do subsolo, têm um custo maior, exigindo perfuração mais profunda, 


\section{REMOA}

tubos para condução e uma bomba para retirá-la do solo e levá-la até o reservatório, para só depois chegar às casas, como afirma, ainda, Chiaradia (2003).

Outro conceito a ser tratado é de água limpa ou natural, sendo que o certo é água potável, que é a que se consome, sendo limpa, transparente, sem cheiro, nem cor, que não contenha vírus, microorganismos patogênicos, ovos de vermes, agrotóxicos, metais pesados ou outras impurezas. Como explica Cavinatto:

Para ser potável a água deve ser límpida e não apresentar cheiro ou sabor desagradável. Porém seu aspecto bem como o local de coleta não são suficientes para indicar se ela é apropriada ou não para o consumo. Esse critério muitas vezes é enganoso, pois a água límpida pode estar repleta de micróbios. Mesmo um poço que produza água transparente pode estar recebendo seres patogênicos de outras fontes contaminadas. (CAVINATTO, 1992, p. 31).

Muitas cidades sem infraestrutura veem sua população multiplicar-se e se instalar de maneira desordenada e em lugares muitas vezes impróprios. Surgem problemas de falta de moradia, com saneamento básico precário, causando surtos epidêmicos, poluição das águas e do ar devido ao processo de industrialização. Além disso, a popularização dos automóveis, com congestionamentos de trânsito e excesso de resíduos gerados, também passa a ser um problema ambiental e de saúde.

Pereira (2010) define saneamento básico como atividade relacionada com o abastecimento de água potável, o manejo de água pluvial, a coleta e o tratamento de esgoto, a limpeza urbana, o manejo de resíduos sólidos e o controle de pragas e de qualquer tipo de agente patogênico, visando à saúde das comunidades. O serviço de saneamento é prestado por empresas públicas ou privadas e é essencial para a população manter a qualidade de vida, pois $6 \%$ das doenças no mundo são causadas por consumo de água não tratada e pela falta de coleta de esgoto. Acrescenta:

O saneamento básico é invariavelmente uma atividade econômica monopolista em todos os países do mundo, já que seu monopólio é um poder típico do Estado, sendo que este pode delegar à empresas o direito de explorar estes serviços através das chamadas concessões de serviços públicos. Tendo em vista a dificuldade física e prática em se assentar duas ou três redes de água e/ou esgotos de empresas diferentes no equipamento urbano, geralmente, apenas uma empresa, seja pública ou privada, realiza e explora economicamente esse serviço. (PEREIRA, 2010).

A Constituição Federal de 1988 reconhece a saúde como um direito social e um dever do Estado, garantindo a toda a população o acesso ao atendimento médico. Conforme a Carta Magna, o modelo de saúde pública não trata apenas da doença, mas da prevenção e do bem estar físico, mental e social. O Estado deve disponibilizar ações e serviços que recuperem os pacientes, promovam a saúde e protejam os cidadãos, como diz Zocchi (2010).

Nos dias atuais, saúde significa bem estar físico e mental, ou seja, a saúde resulta não só do equilíbrio de todas as funções que ocorrem no corpo, mas também da harmonia do ser humano com o meio ambiente. As pessoas de um modo geral têm prestado mais atenção aos impactos que o homem causa na natureza, valorizando as questões ecológicas e lutando pela preservação do meio ambiente. Dessa forma, cresce a intenção de preservar a natureza, lutar contra a degradação 


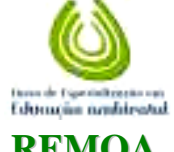

LANG \& LINK, vol.(4), n4, p. 582-595, 2011. Monografias Ambientais $\quad(e-I S S N$ : 2236-1308)

REMOA

ambiental e expandir a consciência ecológica, para que haja uma relação de harmonia com o Planeta.

Melhor que curar doença é não tê-la, melhor do que entrar em falência para depois sanar é investir em prevenção, que sempre tem retorno multiplicado (CAVALCANTI, 2010). A prevenção se divide em dois grandes componentes: a promoção de saúde, que lida com as causas das doenças que dependem de fatores ligados ao estilo de vida; e as atividades de proteção à saúde, quando se busca a intervenção específica sobre alguns riscos, como campanhas através de vacinação, conforme Carvalho (apud CAVALCANTI, 2010).

\section{Legislação ambiental}

Nos últimos anos, a preservação e a conservação ambiental estão ganhando destaque na sociedade, com a regularização da legislação ambiental brasileira. Percebe-se que o homem ainda está longe de reconhecer essa política pública, pois está descumprindo o princípio do desenvolvimento sustentável, colocado na Constituição Brasileira, conforme Araújo (2010), que destaca o embasamento na Declaração de Estocolmo - 72 e no Relatório de Bruntland, que declara que tanto o poder público quanto a população devem defender e preservar o ambiente ecologicamente equilibrado, que é um bem de uso comum do povo e essencial a uma sadia qualidade de vida.

Ou seja, a atividade econômica deve estar em sintonia com a preservação do meio ambiente, havendo equilíbrio entre a liberdade econômica e o respeito ao equilíbrio ecológico, conseguindose, assim, a preservação dos recursos naturais. Conforme Araújo (2010), no artigo 23 da Constituição Federal Brasileira coloca que:

Art. 23. É competência comum da União, dos Estados, do Distrito Federal e dos Municípios:

III - proteger os documentos, as obras e outros bens de valor histórico, artístico e cultural, os monumentos, as paisagens naturais notáveis e os sítios arqueológicos;

IV - impedir a evasão, a destruição e a descaracterização de obras de arte e de outros bens de valor histórico, artístico ou cultural;

$\mathrm{VI}$ - proteger o meio ambiente e combater a poluição em qualquer de suas formas;

VII - preservar as florestas, a fauna e a flora;

$\mathrm{XI}$ - registrar, acompanhar e fiscalizar as concessões de direitos de pesquisa e exploração de recursos hídricos e minerais em seus territórios.

Mas isso não está ocorrendo, pois o homem está provocando um dos problemas mais graves ao ambiente, gerado pela falta de saneamento básico, ou seja, pela falta de um conjunto de ações que visa à modificação das condições ambientais, com a finalidade de prevenir a difusão de transmissores de doenças e de promover a saúde pública e o bem-estar da população, o que inclui fornecimento de água limpa e tratamento de esgoto, segundo Zocchi (2010).

Para o mesmo autor, nas últimas décadas aumentou a ação danosa do homem sobre o ambiente, poluindo o solo, a água e o ar; também destruindo as florestas e matas, acelerando a extinção das espécies, aumentando o consumo de recursos naturais em uma velocidade alucinante. Ou seja, $80 \%$ da população mundial utilizam mais recursos naturais do que é produzido em seu território.

A busca por sustentabilidade faz refletir sobre os limites do crescimento econômico e sobre o uso abusivo dos recursos naturais, que causam a escassez de alimentos e o esgotamento dos recursos naturais não renováveis. Portanto, desenvolvimento sustentável é aquele que satisfaz as necessidades presentes, sem comprometer a capacidade das gerações futuras de suprir suas próprias necessidades. Surge, dessa forma a idéia de capital natural, formado pelas nascentes e 


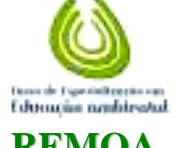

LANG \& LINK, vol.(4), n4, p. 582-595, 2011. Monografias Ambientais $\quad($-ISSN: 2236-1308)

REMOA

mananciais de água, jazidas minerais e florestas nativas preservadas, que junto com o capital humano e financeiro possibilitam a produção de bens e serviços.

Mas o homem ainda não tem essa consciência, e com o crescimento da população e com o maior consumo de matéria-prima, a quantidade de resíduos sólidos e líquidos tornou-se uma ameaça ambiental e social. O acúmulo de lixo provoca a poluição e a contaminação do solo e da água, a liberação de gases do efeito estufa e a proliferação de insetos transmissores de doenças como diarréia, amebíase e parasitoses. O lixo jogado no meio ambiente também pode provocar enchentes, por obstruir os cursos de água.

A poluição das águas é causada pelo lançamento de efluentes industriais, agrícolas, esgoto doméstico e resíduos sólidos. Isso compromete a qualidade das águas superficiais e subterrâneas. Os rios e lagos são os ambientes mais ameaçados, por causa da construção de hidrelétricas e da canalização. Os esgotos domésticos, ricos em matéria orgânica, provocam o crescimento de algas que formam camadas na superfície da água, impedindo a entrada de luz e de oxigênio. Os nitratos presentes nos fertilizantes e no esgoto humano contaminam as águas subterrâneas. A perfuração sem controle de poços em regiões sem manancial acelera a contaminação dos lençóis. Zocchi esclarece esse assunto:

[...] Brasil, parte do esgoto é despejada sem tratamento em rios, mares, lagos e mananciais. Segundo a PNAD do IBGE, em 2008 apenas 52,5\% dos domicílios brasileiros contavam com coleta de esgoto. No restante, os dejetos iam para fossas sépticas, fossas secas ou eram lançadas no ambiente. O quadro se agrava na medida em que $7,2 \%$ dos municípios não dispunham de abastecimento de água tratada. (ZOCCHI, 2010, p. 127).

Surge a importância do princípio do poluidor-pagador, ou seja, todo aquele que der causa a um dano ambiental tem de pagá-lo. O poluidor tem o dever de arcar com as despesas decorrentes do dano ambiental. Havendo dois caminhos, sendo o primeiro de caráter preventivo, quando se busca evitar a ocorrência de danos ambientais; e o segundo de caráter repressivo, quando ocorrido o dano este deve ter reparação. Conforme a Constituição Federal Brasileira de 1988, no artigo 225 , no parágrafo 3 , as condutas e atividades consideradas lesivas ao meio ambiente sujeitarão os infratores, pessoas físicas ou jurídicas, a sanções penais e administrativas, independentemente de reparar danos. (Araújo, 2010)

Como disposto no artigo 14 , parágrafo $1^{\circ}$ da Lei $6.938 / 81$, "Sem obstar a aplicação das penalidades previstas neste artigo, é o poluidor obrigado, independentemente de existência de culpa, a indenizar ou reparar os danos causados ao meio ambiente e a terceiros, afetados por sua atividade". ( Idem) A miséria também acompanha o desenvolvimento, por exemplo, pessoas de uma mesma cidade apresentam grandes desníveis culturais e socioeconômicos.

A urbanização acelerada e desordenada, que se caracteriza pela concentração de grandes contingentes populacionais e das atividades econômicas em áreas relativamente pequenas, além de um modelo de desenvolvimento econômico marcado pelo uso abusivo, e por vezes predatório dos recursos naturais, tem colaborado para a rápida e intensa degradação das cidades.

É conhecido o resultado dessa falta de cuidado, do crescimento populacional desestruturado, ou seja, aumenta-se o consumo de recursos naturais que não se repõe na mesma velocidade no ambiente, deixando-o degradado. Os ecossistemas são sistemas dinâmicos que resultam da interdependência entre os fatores físicos do meio ambiente, como a atmosfera, o solo e a água e os seres vivos que o habitam.

Pesquisadores, dentre eles Zocchi (2010), defendem a ideia de pagar pelo que devemos preservar, ou seja, o pagamento por serviços ambientais, o PSA, que está sendo usado no sequestro de carbono ou de mananciais de água limpa. Na cidade de Extrema, no sul de Minas Gerais, a 
prefeitura está pagando a agricultores para preservarem as matas ciliares e manterem as águas das nascentes limpas, para formar o Sistema Cantareira, que irá abastecer a região metropolitana de São Paulo.

Existem leis e políticas ambientais que garantem o uso sustentável da floresta, evitando o desmatamento; conciliando a manutenção da floresta com a geração de emprego e renda, com as operações de repressão, a recuperação das áreas degradadas por meio do reflorestamento, regularização fundiária na região e o pagamento de serviços ambientais prestados pela Amazônia para o Brasil e para o resto do mundo.

Por exemplo, no Amazonas está sendo realizado o programa Bolsa-floresta, desde 2007, que incentiva a população a deixar a floresta em pé, para que haja a regulação do clima e armazenamento de carbono, buscando novas fontes de renda, como a produção sustentável de mel, castanhas, frutas, peixes, entre outras. Dessa forma a exploração de madeira irá melhorar o IDH por dez anos e a pecuária em área desmatada, que fica no solo pobre, por cinco anos. Outra iniciativa é a moratória da carne, que é um acordo de grandes frigoríficos de não adquirirem carne vinda de pastos de desmatamento ou de reservas ambientais da Amazônia Legal para exportação. Bem como acordo de rastrear a origem do gado, para evitar a proliferação da febre aftosa nos últimos anos, como se vê em Zocchi (2010).

O princípio da prevenção / precaução, descrito no artigo 225 da Constituição Federal, em seu caput, determina o dever do poder público e da coletividade de proteger e preservar o meio ambiente para as presentes e as futuras gerações, de maneira que é melhor prevenir do que remediar. O sistema de prevenção brasileiro ocorre através do licenciamento ambiental, que se dá em três etapas: licença prévia, licença de instalação e de operação; já o princípio da precaução, que é tido como haver ausência de absoluta certeza científica, não deve ser utilizado como razão para postergar medidas eficazes e economicamente viáveis para prevenir a degradação ambiental, sendo mais bem compreendido no Princípio 15 da Declaração do Rio de Janeiro (ECO-92). Esse está se referindo a riscos potenciais que, pela falta de um anterior conhecimento, não podem ser identificados. ( Araújo, 2010)

Veja-se que, diante de uma dúvida em relação aos efeitos nocivos de uma atividade, a fim de proteger o homem na sua individualidade e coletividade, sempre integrado ao meio ambiente, ela deve ser evitada ou controlada. Os impactos da urbanização são muitos, deve-se sensibilizar a população para que tenha qualidade de vida e não somente recupere os ecossistemas degradados. Como confirma Araújo (2010), a Constituição Federal, em seu artigo 225, caput, estabeleceu que "todos têm o direito ao meio ambiente ecologicamente equilibrado, bem de uso comum do povo". Ou seja, a sociedade deve ser considerada como verdadeira e única titular do patrimônio ambiental.

O princípio da democracia é muito importante para todos e deve ser conhecido pela população, que encontrará a informação de que é necessária sua participação na proteção e preservação do meio ambiente. Isso escrito na Constituição Federal, fica declarado que a titularidade é do povo.

\section{RESULTADOS E DISCUSSÕES}

$\mathrm{Na}$ interpretação e análise dos dados obtidos mediante a apuração dos questionários quantitativos, considerou-se a incidência de respostas em comum, que possibilitaram o agrupamento e a classificação dos resultados representados em gráficos.

Conforme o questionário realizado, foram apurados resultados que configuram como estão organizadas as famílias dos alunos, sendo que 5 famílias são compostas por 2 a 4 integrantes, 4 
famílias por 4 a 6 integrantes e somente 1 por mais de 6 integrantes. Isso denota que as famílias são pequenas, sendo 26 homens para 21 mulheres. Ou seja, as famílias são constituídas por mais homens que mulheres, o que se percebeu também na turma, que foi composta por $80 \%$ de meninos e $20 \%$ de meninas.

Para os alunos, quanto maior o grau de estudo, melhor é a chance de conseguirem um emprego com melhor remuneração, pois na zona urbana da cidade as indústrias e o comércio prevalecem; para entrar nesses setores está sendo exigido dos mesmos um estudo cada vez mais especializado, não bastando ter o ensino fundamental, hoje o pré-requisito é ensino médio, técnico ou superior, com domínio em informática, além do que, várias empresas pedem um conhecimento em língua estrangeira.

Ao analisar o item "Aonde você mora existe" (Figura 1), percebeu-se que as famílias estruturaram suas moradias contemplando-as com quartos individuais, cozinha, sala e banheiro dentro de casa. A maioria das crianças não dorme mais com seus pais, o que é um avanço para a individualidade delas. Além disso, a estrutura representa um cuidado maior com a saúde, já que podem contar com banheiro, água encanada e energia elétrica em suas casas, o que Ihes proporciona muitas comodidades como chuveiro elétrico, televisão e eletrodomésticos.

Não se pode falar o mesmo de calçamento e coleta de lixo, pois apenas 3 famílias possuem e as demais moram em localidades do interior que não contam semanalmente com o serviço. Quanto a esgoto, 3 têm em sua residência e 7 possuem fossa séptica, para acomodar os dejetos de suas casas. Os mesmos alunos que contam com recolhimento de lixo e calçamento, contam com esgoto, o restante descarta os dejetos em fossas sépticas, que muitas vezes foram mal projetadas e acabam indo diretamente no ambiente, provocando proliferação de insetos nocivos e doenças. Quanto ao saneamento, a maioria dos alunos não percebeu que há problemas, dado esse que demonstrou a necessidade de trabalhar com os mesmos o conceito de saneamento básico, de verificarem se todos contam com água tratada ou potável em casa, se os dejetos do vaso sanitário são jogados no ambiente ou se são depositados em fossas sépticas.

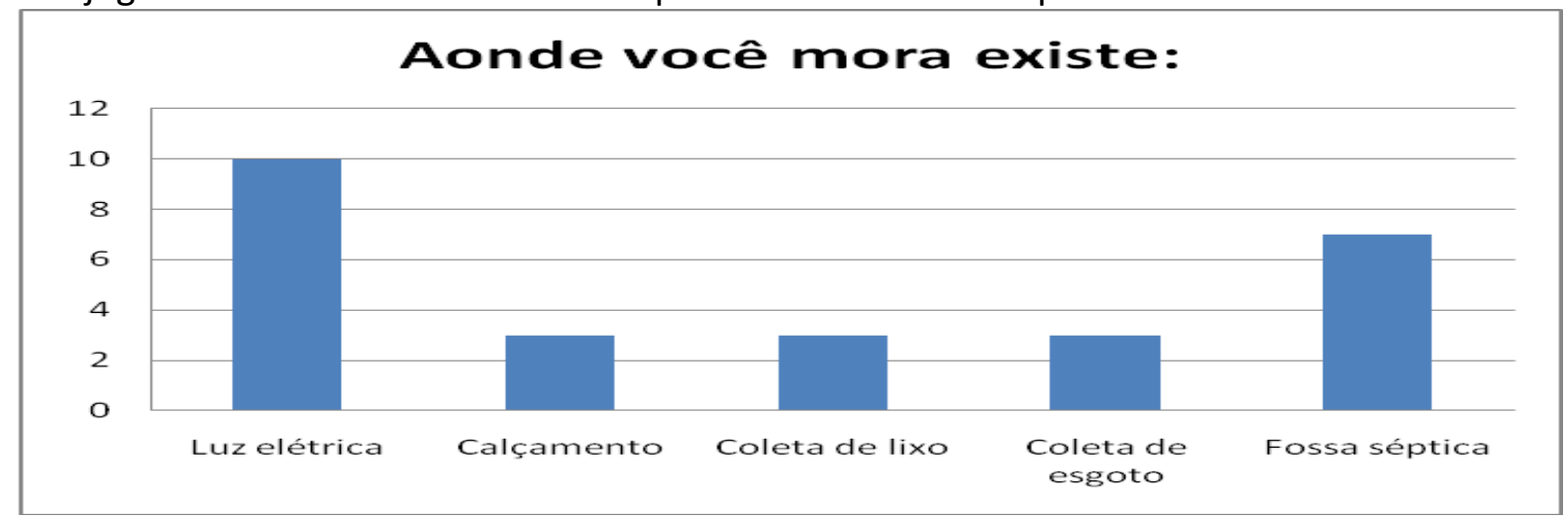

Figura 1- Infraestrutura da casa dos alunos do 6 o ano da EMEF 21 de Abril - Panambi (RS).

Pesquisa realizada em 19 de abril de 2011.

Analisando o item "A água que você utiliza" (Figura 2), percebeu-se que 6 alunos recebem água em suas casas de poço artesiano, 3 da Corsan e 1 de poço. Como a maioria mora no interior, possuem a rede da água de poço artesiano, sendo que são vários poços que abastecem essas residências, sendo vistoriados pela vigilância sanitária e realizada análise anual da qualidade da água. Ao serem questionados sobre a água que consomem 6 declararam ser natural, 3 tratada e 1 limpa, nenhum declarou ser pura.

Para os alunos não estavam claros os conceitos em relação à água e após leituras e análise, definiu-se que os que moram na zona urbana da cidade consomem água tratada, que é distribuída 
REMOA

pela Corsan - Companhia Riograndense de Saneamento, e os alunos da zona rural que consomem água de poço artesiano têm água potável, sendo que o reservatório recebe fiscalização regular. Os alunos compreenderam que a água é imprescindível para o homem e a vida na terra e se continuar sendo consumida sem controle vai tornar-se um produto de consumo cada vez mais escasso, sendo que será necessário comprá-la a altos valores.

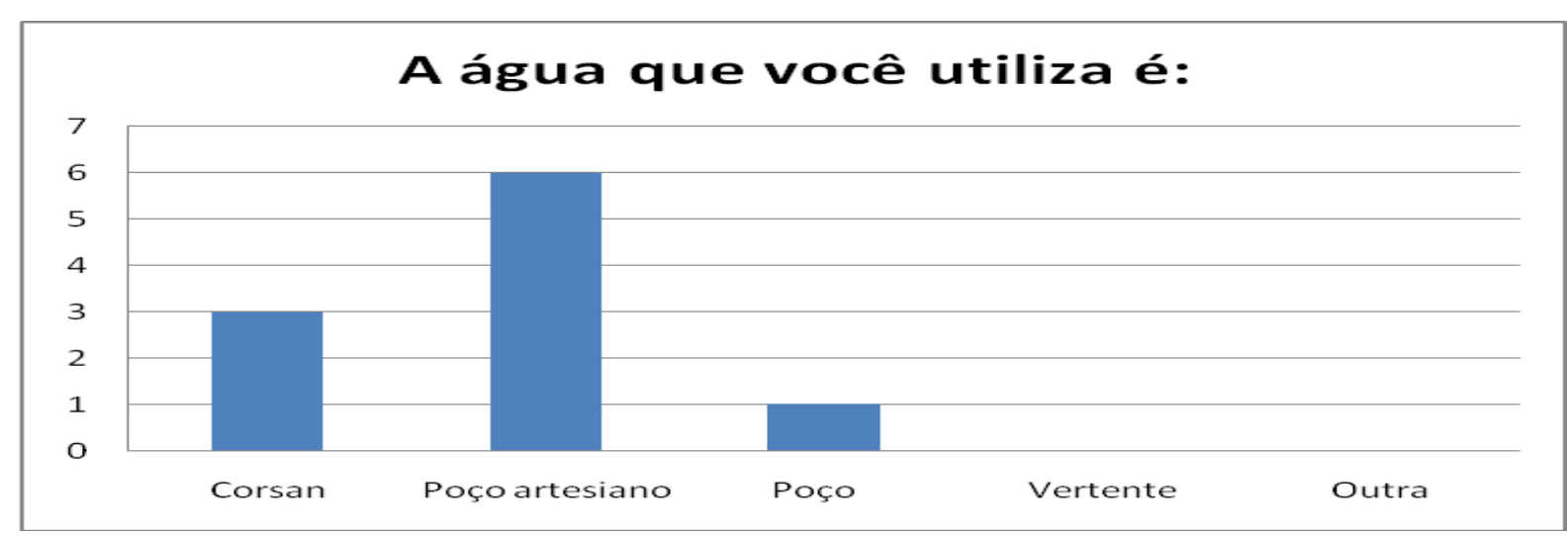

Figura 2 - Procedência da água que é consumida na casa dos alunos do 6 ano da EMEF 21 de Abril - Panambi (RS). Pesquisa realizada em 19 de abril de 2011.

O papel do educador ambiental é incentivar os educandos a acharem soluções para seus problemas, desde o mais simples até o mais complexo. Percebeu-se que o lixo é um problema constante para os alunos, analisando as respostas para o item: "O que fazem com o lixo" (Figura 3), ficou claro que entre eles, 7 famílias fazem a separação de lixo entre orgânico e reciclável, mas apenas 2 possuem recolhimento semanal e 5 descartam perto de casa. Ou seja, o lixo acaba ficando jogado no ambiente e saber qual é o destino final do lixo produzido pelas famílias, trazer soluções e propor alternativas é o papel do educador ambiental.

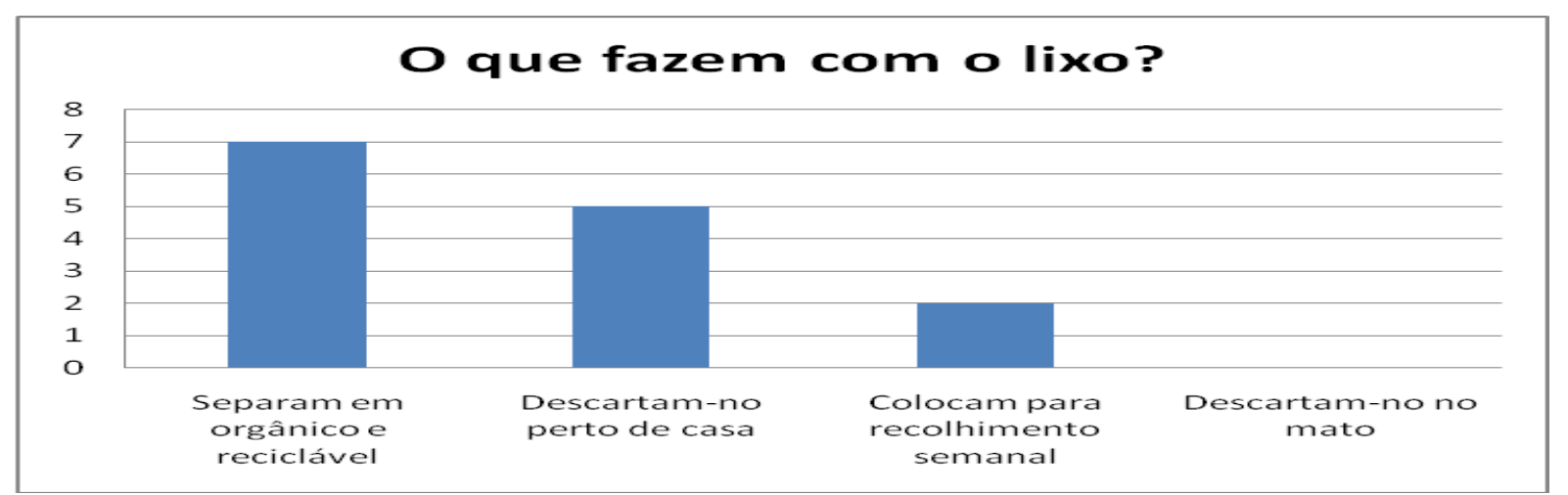

Figura 3 - Forma de descarte do lixo das casas dos alunos do 6 ano da EMEF 21 de Abril - Panambi (RS). Pesquisa realizada em 19 de abril de 2011.

Esse problema os inquieta, já que na escola eles aprendem que o lixo deve ser separado em orgânico e reciclável, coletado e, automaticamente, deve-se dar o destino correto para o mesmo. O maior problema encontrado pelos alunos e pelo professor da turma foi o destino do papel higiênico, para o que foi proposta incineração, pelo responsável da Usina de Reciclagem de Lixo da cidade, e que os alunos estão realizando em casa e a escola também está utilizando, mas como se estudou, causará a poluição do ar. 


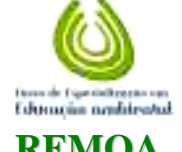

LANG \& LINK, vol.(4), n4, p. 582-595, 2011. Monografias Ambientais (e-ISSN:2236-1308)

REMOA

A bibliografia especializada que propunha formas de descarte diferenciado da incineração foi analisada pelos alunos. A primeira analisada foi a incineração do papel higiênico, proposta pelo responsável pela Usina de Reciclagem. O estudo foi feito com base em Oliveira (2005) e no texto "Qual é o Destino do Lixo Urbano e como Diminuir seu Impacto no Ambiente". Percebeu-se que para que a incineração ocorra corretamente é necessária a construção do incinerador, que foi projetado por Alfred Fryer, em 1874, na Inglaterra. Mas seu custo é muito elevado, e se a combustão não for completa, podem ser lançados no ambiente monóxido de carbono e partículas, como fuligem ou negro fumo, que são altamente tóxicos, poluindo os rios, trazendo mau cheiro e poluição visual.

A segunda possibilidade analisada foi o descarte através da colocação do papel higiênico na bacia sanitária, já que o mesmo é de fácil decomposição e o processo evita o risco de infecções para as pessoas que realizam a coleta. Foi necessário analisar o sistema de esgoto sanitário, sendo que os textos de Leite (2011) e de Lisboa (2011) colaboraram para esclarecer qual o melhor tipo de tratamento a ser realizado, pois ele varia de cidade para cidade e de casa para casa. Concluiu-se que na maioria das casas isso não é possível, porque é utilizada a fossa séptica e como o papel será decomposto na mesma, que tem espaço pequeno, ela não comportará e logo estará cheia, ficando entupida, sendo necessária a sua limpeza e consequentemente, gastos maiores para os pais e para o ambiente, bem como o maior consumo de água para que aja o escoamento do papel. O terceiro objeto de análise foi a compostagem, conforme Oliveira (2005), que coloca a forma de realizá-la, juntamente com os restos de alimentos produzidos diariamente nas casas e na escola. A ideia foi bem aceita pela turma, pois o composto pode ser utilizado em vasos de flores, adubação de hortas e consequentemente o papel higiênico deixa de ser um problema e torna-se uma solução.

Com o descarte do lixo no ambiente, surge o aparecimento de animais nocivos ao homem, que causam vários problemas, como os alunos colocaram, pois sofrem problemas com répteis cobras, o que foi constatado por 8 alunos, 7 alunos indicaram os insetos pulgas/percevejos/pernilongos, 5 citaram aracnídeos - aranhas /escorpiões e apenas 1 colocou a incidência de roedores- rato/ratão do banhado em sua casa ou galpões e celeiros. Percebeu-se que se o lixo for descartado corretamente, diminuirá consideravelmente o surgimento de animais nocivos nas residências dos alunos e, consequentemente, das doenças, e a qualidade de vida melhorará em todos os níveis.

Ao finalizar, foi perguntado se os alunos conversam com seus pais a respeito das questões relacionadas ao meio ambiente, sendo que 6 disseram que não, 1 disse que sim e 3 não responderam. Com essas respostas, percebeu-se o pouco diálogo existente entre pais e filhos em relação ao ambiente. Com o trabalho houve um questionar de atitudes e ações, fazendo com que os alunos procurassem soluções para si, suas famílias e o ambiente que os cerca.

As principais soluções foram embasadas em Feijó (2008), segundo o qual em casa deve-se reutilizar os recipientes plásticos de produtos industrializados destinados ao consumo humano (alimentos); economizar água, energia elétrica, gás, combustível, alimentos e outros; ajudar a implantar e participar da coleta seletiva de lixo na comunidade e no município; evitar queimar folhas e galhos de árvores nos pátios particulares e terrenos baldios. As queimadas emitem gases que podem ser tóxicos e, quando lançados na atmosfera, contaminam o meio ambiente; ao lavar o automóvel e os pisos, é preciso evitar o uso de mangueiras; realizar a atividade com o auxílio de baldes ou outros recipientes, pois, assim, será evitado o gasto excessivo de água.

Na comunidade não se deve jogar lixo em terrenos baldios, rios e córregos. Isso poderá causar enchentes, além de apresentar perigo de contaminação por ratos e insetos; deve-se separar os 


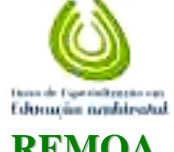

LANG \& LINK, vol.(4), n4, p. 582-595, 2011. Monografias Ambientais $\quad(e-I S S N$ : 2236-1308)

REMOA

resíduos de construção civil, pois poderão ser utilizados para pavimentação, contenção de encostas e na construção de casas populares; e separar o lixo produzido buscando alternativas de destinação ecologicamente corretas. (FEIJÓ, 2008).

A educação ambiental necessita vincular os processos ecológicos aos sociais, na forma de intervir na realidade e de existir na natureza, então, acredita-se que o que se aprende de pequeno não se esquece. Assim, para que a natureza permaneça em equilíbrio, a educação ambiental deve se iniciar na educação infantil, onde as crianças estão aprendendo os conhecimentos básicos, as primeiras regras, que fixarão no decorrer da sua vida escolar e, consequentemente, poderão incluir sua família.

\section{CONSIDERAÇÕES FINAIS}

Conforme a metodologia proposta para este estudo e os resultados obtidos, é possível tecer algumas considerações finais, retomando que o problema inicial que embasou o projeto de pesquisa foi fazer com que os alunos reconhecessem o meio ambiente como espaço de convivência dos seres vivos, apontando possibilidades e atitudes de conservação e preservação deste meio como um todo; contribuindo assim, para a sensibilização sobre a importância do cuidado com a água, o saneamento, a saúde da população do local, bem como com os impactos sociais das doenças e outros problemas que ocorrem devido à falta de cuidados, o que foi alcançado.

Mesmo sendo um problema amplo, conseguiu-se captar a mudança de percepção a partir da segunda conversa com os alunos, pois os mesmos colocaram que com a discussão proposta viram o ambiente com novo olhar, compreenderam como o ser humano interfere no mesmo e o que eles, como alunos e filhos, podem fazer para melhorar o ambiente em que vivem.

O trabalho realizado permitiu que os alunos, tendo o olhar do educador ambiental como apoio, conseguissem sensibilizar os adultos com os quais convivem (seus pais, avós ou responsáveis), para realizarem a mudança de mentalidade e valores em relação ao meio ambiente em que vivem. Eles puderam conscientizar-se da importância dos esforços de cada um para a própria sobrevivência e das futuras gerações, compreendendo a importância que a população tem em defender e preservar o ambiente ecologicamente equilibrado, pois o mesmo é um bem de uso comum e essencial para uma sadia qualidade de vida. Isso se dá, observando o cuidado com sua saúde e o descuido do ambiente em que vivem com seus familiares, seu entorno e na escola.

$\mathrm{Na}$ intervenção realizada na Escola, os alunos receberam material bibliográfico, mapas, reportagens de jornais e, com os questionamentos, observaram o local onde vivem, percebendo como a exploração humana degrada o ecossistema. Além disso, reconheceram os impactos sociais que são acarretados: o aumento das doenças, a falta de saneamento básico e o descarte do lixo no ambiente, que causam as constantes enchentes na cidade e na região. Portanto, os alunos perceberam que cada um deve fazer a sua parte e isso só pode acontecer quando houver a revisão de valores e atitudes, compreendendo assim que o desenvolvimento sustentável nunca acontecerá se continuar a degradação do meio ambiente.

Com o questionamento inicial, identificaram os problemas vividos por eles, relacionados com a água e saneamento básico, os quais trazem prejuízos à saúde em função do descuido ambiental. Eles perceberam que em casa deveriam ter um cuidado maior com a água e realizar o descarte correto do esgoto produzido pela sua família. Assim, compreenderam que seu papel é proteger o meio ambiente, combatendo a poluição, preservando as florestas, a fauna e a flora que os rodeia, 


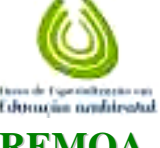

LANG \& LINK, vol.(4), n4, p. 582-595, 2011. Monografias Ambientais $\quad($-ISSN: 2236-1308)

REMOA

bem como acompanhando e fiscalizando a exploração da água que consomem diariamente, tanto de poços artesianos quanto da Corsan, para a melhoria de sua saúde, evitando as doenças.

Com o término do trabalho, foi alcançado o objetivo de buscar a sensibilização das crianças em defesa do ecossistema em estudo, sendo que foram disponibilizados referenciais da legislação ambiental municipal e federal, em que identificaram soluções que modificaram a sua atitude e de seus familiares com relação ao ambiente.

\section{REFERÊNCIAS}

Albuquerque, C. M. de S.; OliVeirA, C. P. F. de. Saúde e doença: significações e perspectivas em mudança. Disponível em: <www.ipv.pt/millenium/millenium25/25 27.htm>. Acesso em: 22 abr. 2011.

ARAÚJO, L. E. B. de. Ordenação jurídica do ambiente. Santa Maria: UFSM. 2010. (Apostila).

CAVALCANTI, D. Para virar a mesa. Revista Vida e Saúde, São Paulo, p. 11, set. 2010.

CAVINATTO, V. M.. Saneamento básico: fonte de saúde e bem-estar. São Paulo: Moderna, 1992.

CHIARADIA, A de. Mini-manual de pesquisa: biologia. Uberlândia: Claranto, 2003, p. 43-78.

FEIJÓ, C.C.C. ( Org.). A sociedade, meio ambiente e cidadania. Londrina: UNOPAR, 2008, p.151-171.

LAMPARELLI, C. M.. Cooperação intermunicipal e desenvolvimento: soluções regionais para o desenvolvimento municipal. São Paulo: CEPAM, 1999, p. 229-236.

LEITE, F. A. A influência do lançamento de papel higiênico em bacia sanitária no consumo de água em edifícios de escritórios. Disponível em: <www.usp.br/siicusp/Resumos/16Siicusp/1561.pd>. Acesso em: 16 abr. 2011.

LEITE, F. A.; OLIVEIRA, L. H. de. Avaliação do consumo de água em bacia sanitária quando do descarte de papel higiênico. Disponível em <http://www.cesec.ufpr.br/sispred/atas/artigos/215 final.pdf>. Acesso em: 17 abr. 2011.

LISBOA, S. Triste destino do papel higiênico. Disponível em: < http://ocapitaoplaneta.blogspot.com/2011/02/o-tristedestino-do-papel-higienico.html> Acesso em: 18 abr. 2011.

LOUREIRO, C. F. B. Educação ambiental crítica: contribuições e desafios. Brasília: UNESCO, 2007 p. 65-76.

MAGNOLI, D. Geografia: a construção do mundo: geografia geral e do Brasil. 1. ed. São Paulo: Moderna, 2005.

MALVESSI, R. Cuidar da terra, um compromisso de fé. Revista Mundo Jovem, ano 45, n. 375, p. 9, abr. 2007.

NISHIJIMA, T. Educação ambiental: água e solos. UFSM, 2010, p.13.

OLIVEIRA, A. M. G. Compostagem caseira de lixo orgânico doméstico. Bahia: Ministério da Agricultura, Pecuária e Abastecimento, 2005.

PRADO, A. Educação ambiental formal e não formal. VII Semana Científica do Curso de Turismo da Faculdade Vale do Aporé. Disponível em: www.ficms.com.br/.../educacao ambiental formal e nao formal.ppt. Acesso em: 17 out. 2010.

PEREIRA-CARDOSO, F. D. et al. Prevalência de Enteroparasitoses em Escolares de 06 a 14 Anos no Município de Araguaína - Tocantins. Revista Eletrônica de Farmácia, v. 7, n.1, p. 54-64, 2010. Disponível em: http://pt.wikipedia.org/wiki/Saneamento\#Refer.C3.Ancias Bibliogr.C3.A1fias. Acesso em: 22 abr. 2011.

QUAL é o destino do lixo urbano e como diminuir seu impacto no ambiente. Disponível em: <1.http://intra.vila.com.br/sites 2002a/urbana/susana/sitedestino.htm> Acesso em: 17 abr. 2011.

ZOCCHI, P. Poluição. Almanaque Abril, São Paulo: Abril, 2010, p. 203-204. . Saúde. Almanaque Abril, São Paulo: Abril, 2010, p. 139-160. . Urbanização. Almanaque Abril, São Paulo: Abril, 2010, p.12. 